\title{
Effects of the terminal donor unit on the photovoltaic parameters of benzocarbazole-based dyes for DSSCs: DFT/TD-DFT investigations
}

\author{
Hanane Etabti ${ }^{1, *}$, Asmae Fitri ${ }^{1}$, Adil Touimi Benjelloun ${ }^{1}$, Mohammed Benzakour ${ }^{1}$, and Mohammed Mcharfi $^{1}$ \\ ${ }^{1}$ LIMAS, Faculty of Sciences Dhar el Mahraz, Sidi Mohamed Ben Abdellah University, Fez, Morocco
}

\begin{abstract}
In this paper, a computational study on five organic p-conjugated molecules based benzocarbazole $(\mathrm{BC})$ is reported. These new dyes were characterize theoretically by density functional theory (DFT) and time-dependent (TD-DFT) approaches. Different electron side groups were introduced as a terminal donor to investigate their effects on the electronic structure; the HOMO, LUMO, free energy of electron injection $\left(\Delta \mathrm{G}_{\text {inject }}\right)$, free energy regeneration $\left(\Delta \mathrm{G}_{\text {reg }}\right)$, open circuit voltage $\left(V_{\text {oc }}\right)$, the gap energy and UV-visible absorption spectra analysis of these dyes have been reported and discussed. The calculated results show that dye M3 with phenoxazine as a terminal donor groups can be used as a potential donor of electron in DSSCs, due to its best electronic and optical properties and good photovoltaic.
\end{abstract}

\section{Introduction}

The solar energy, as a cleaner and cheaper renewable energy has become a very popular research topic over the last decades to solve the energy crisis [1]. In this context, various types of solar cells have been rapidly developed in particular dye-sensitized solar cells (DSSC), because of their advantages such as low production costs, high efficiency and easy manufacturing process [2,3]. Generally, the dye sensitizer is the key element of DSSCs because it is responsible for the collection of light and the injection of electrons into the conduction band (CB) of the $\mathrm{TiO}_{2}$ semiconductor, which plays a significant role in high power conversion efficiency (PCE), and therefore a high efficiency of conversion of solar energy into electricity [4,5]. During the last decade, mineral-free organic dyes have been developed which can be considered as a good alternative to the ruthenium complexes used in DSSC [6] due to the scarcity of ruthenium and its high toxicity, but in general mineral complexes still contribute to the development of DSSC [7]. On the other hand, mineral-free dyes are characterized by the ability to control their photoelectric and electrochemical properties, in addition to their ease of installation, as well as their color, lightness and high molar absorption coefficient [8]. A conversion efficiency of $14 \%$ of the DSSC with metal-free sensitizer was achieved and remains the highest to date [9]. Recently, Han et al. [10] have synthesized a series of three dyes (HQP-F, HQP-B and HQP-S) with a configuration of $\mathrm{D}-\pi-\mathrm{A}$. Wherein benzocarbazole, thiophene and cyanoacrylic acid are taken as the donor, $\pi$-spacer and acceptor, respectively. On the basis of organic dyes HQP-S we want to test whether these molecular can be used in DSSC. For this reason, we have incorporated of various terminal electron donors $(\mathrm{di}, \mathrm{i}=1-4)$, such as; triphenylamine $\left(\mathrm{d}_{1}\right), \quad$ 9,9-Dimethylfluorene $\left(\mathrm{d}_{2}\right)$, phenoxazine $\left(\mathrm{d}_{3}\right)$, and 4-methyl-1,2,3,4-tetrahydro cyclopenta[b]indole $\left(\mathrm{d}_{4}\right)$ to the $\mathrm{BC}$ donor moiety, resulting in the formation of four organic dyes of structure di-D- $\pi-\mathrm{A}(\mathrm{i}=1-4)$, namely $\mathrm{M} 1-\mathrm{M} 4$. Dye $\mathrm{R}$ is the reference dye with single electron-donor (BC). The electronic, optical and photovoltaic properties of the dyes are investigated using density functional theory (DFT) and time-dependent density functional theory (TD-DFT). Fig. 1. (a) illustrates the molecular structures of the organic dyes considered in this paper.

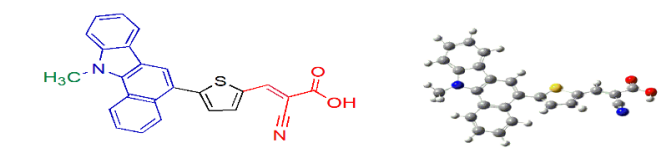

M1

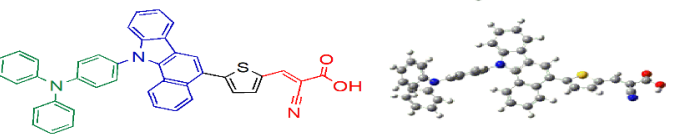

M2

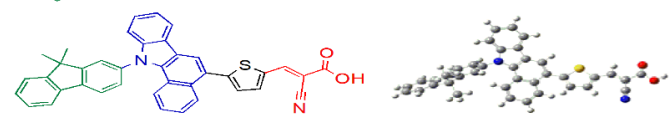

M3

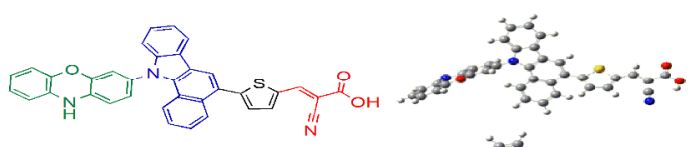

M4

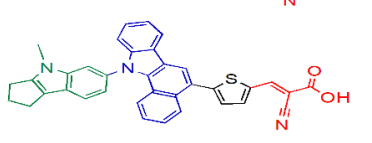

(a)

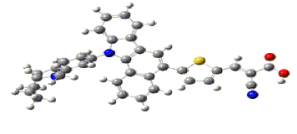

(b)
Fig. 1. (a) Molecular structure of studied dyes; and (b) their optimized geometry with DFT at the B3LYP/6-31G(d,p) level.

*Corresponding author: etabti.hanane@gmail.com 


\section{Methodology}

\subsection{Computational details}

In this work, all the DFT/TD-DFT calculations were performed with Gaussian 09 [11] program package. The ground state structures were optimized using the combination of B3LYP [12] functional, and the 6-31G (d,p) basis set. In addition, frequency calculations have been calculated at the same level, confirming the consistence with an energy minimum for the optimized geometry. The UV/Visible absorption plot of all molecules in chloromethane solvent were obtained by employing IEFPCM (integral equation formalism polarizable continuum model) [13] at TD-DFT/CAMB3LYP/6-31G (d,p) level of theory $[14,15]$.

\subsection{Theoretical background}

The overall efficiency of photo-elution conversion in DSSCs is determined by the integral for $\mathbf{J}_{\mathrm{sc}}$ (short-circuit photocurrent density), $\mathrm{V}_{\mathrm{oc}}$ (open circuit photovoltage), FF (fill factor) and $\mathrm{P}_{\text {inc }}$ (incident photon to current efficiency) from equation [16]:

$$
\eta=\frac{J_{s c} V_{o c} F F}{P_{i n c}}
$$

Therefore, $\eta$ can be enhanced by increasing $\mathrm{J}_{\mathrm{sc}}$ and $\mathrm{V}_{\mathrm{oc}}$.

Theoretically, the maximum open circuit photovoltage $\left(\mathrm{V}_{\mathrm{oc}}\right)$ of the DSSC is determined by the difference between the HOMO of the donor ( $\mathrm{E}_{\mathrm{LUMO}}$ of the dye) and the LUMO of the acceptor $\left(\mathrm{E}_{\mathrm{CB}}=-4.0 \mathrm{eV}\right)$ of the conduction band of semiconductor $\mathrm{TiO}_{2}$ ) according to the following relationship [17]:

$$
V_{o c}=E_{L U M O}-E_{C B}
$$

On the other hand, $\mathbf{J}_{\mathrm{sc}}$ is related to the efficiency of electron injection $\phi_{\mathrm{inj}}$, the charge collective efficiency $\left(\eta_{\text {collect }}\right)$ and the light harvesting efficiency at a given wavelength (LHE) via the following expression [18]:

$$
J_{s c}=\int L H E(\lambda) \phi_{\text {inj }} \eta_{\text {collect }} d \lambda
$$

Another factor determining the efficiency of a DSSC is the response of the dye to the incident light. The light harvesting efficiency (LHE) should be as high as possible to maximize the photocurrent response. The LHE can be expressed as [19]:

$$
L H E=1-10^{-f}
$$

where $f$ represents the oscillator strength of the dye for a given wavelength. Calculation of the electron injection rate from the dye to the $\mathrm{CB}$ of the $\mathrm{TiO}_{2}$ semiconductor and the regeneration of the dye by the electrolyte is very useful for studying the photovoltaic performance. The following equation can be used to calculate the change in free energy (in $\mathrm{eV}$ ) corresponding to electron injection and regeneration $[20,21]$ :

$$
\begin{gathered}
\Delta G_{\text {inject }}=E^{\text {dye* }}-E_{C B}=E^{\text {dye }}-E_{O O}-E_{C B} \\
\Delta G_{\text {reg }}=E_{\mathrm{I} / \mathrm{I}_{3}}-E_{\text {HOMO }}
\end{gathered}
$$

where $E^{\text {dye* }}$ and $E^{\text {dye }}$ are the oxidation energy of the excited dye and the oxidation potential energy of the dye in ground state, respectively. $\mathrm{E}_{00}$ is electronic vertical transition energy corresponding to $\lambda_{\max }$, and $E_{I / I_{3}}$ is the $\mathrm{I}^{-} / \mathrm{I}^{-}{ }_{3}$ redox potential $\left(\mathrm{I}^{-} / \mathrm{I}_{3}^{-}=-4.8 \mathrm{eV}\right)$.

\section{Results and discussion}

\subsection{Geometric and electronic properties}

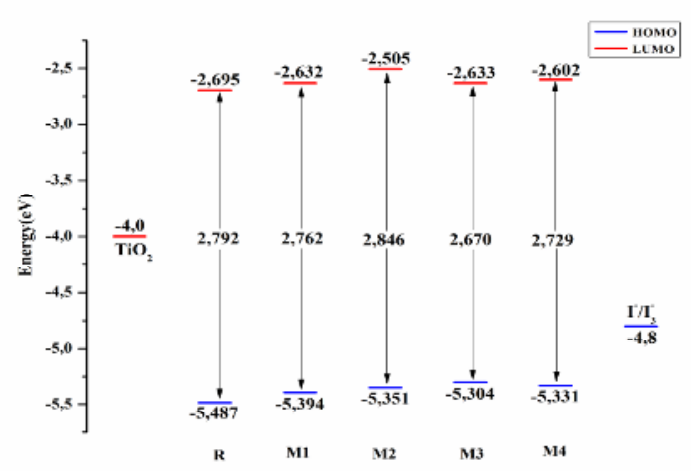

Fig. 2. Schematic energy diagram of all dyes, $\mathrm{TiO}_{2}$ and electrolyte $\left(\mathrm{I}^{-} / \mathrm{I}^{-}{ }_{3}\right)$.

The optimized molecular structure is shows in Fig. 1. (b) The locations of the energy levels of dye sensitizers are very important and they should meet some criterion to match the potential of iodine/iodide redox and the conduction band of $\mathrm{TiO}_{2}$. We analyzed the HOMO and LUMO energy levels of the dyes here, which are demonstrated in Fig. 2. From this figure, it can be seen that the HOMO levels of all the dyes are lower than the redox couple $\mathrm{I}^{-} / \mathrm{I}_{3}^{-}(-4.80 \mathrm{eV}$ [22]), which indicates a favorable thermodynamically regeneration of the oxidized dyes; the LUMO levels are all higher than the conduction band (CB) of $\mathrm{TiO}_{2}(-4.00 \mathrm{eV}$ [23]), which is favorable to a better transfer of electrons from the excited state of the dye to the $\mathrm{CB}$ of $\mathrm{TiO}_{2}$. Compared to $\mathrm{R}$, the incorporation of ancillary donor $(\mathrm{di}, \mathrm{i}=1-4)$ to the electron-donor part $(\mathrm{BC})$ will destabilize the LUMO energies slightly. However, the HOMO levels were affected strongly. The HOMO levels of the binary electron-donor are $0.1 \mathrm{eV}$ positive than that of $\mathrm{BC}$ and decrease in the order $\mathrm{M} 1<\mathrm{M} 2<\mathrm{M} 4<\mathrm{M} 3$, therefore smaller band gaps were received for those four ancillary donor dyes. The differences in electron-donating properties lead to different destabilization of the HOMO levels. The strongly electron donating phenoxazine group in M3 dye effectively narrows the band gap to be $2.670 \mathrm{eV}$. The molecular orbitals HOMO and LUMO of the five dyes are depicted in Fig. 3. We find that for the reference dye only using $\mathrm{BC}$ as the electron-donor; the 
HOMO is populated on the whole of the conjugated molecule, while the LUMO is delocalized through the anchoring cyanoacrylic acid and the bridging thiophene groups. Attaching an ancillary triphenylamine, 9,9Dimethylfluorene, phenoxazine or 4-methyl-1,2,3,4tetrahydro cyclopenta[b]indole groups to $\mathrm{BC}$ can result in a more delocalized distribution of the HOMO patterns, and meanwhile the location of the LUMO mainly remains unchanged. For example, the HOMO of M3 is delocalized over the electron donor of the phenoxazine moiety. For the other three binary electron donor dyes, similar molecular orbital distribution patterns are found.

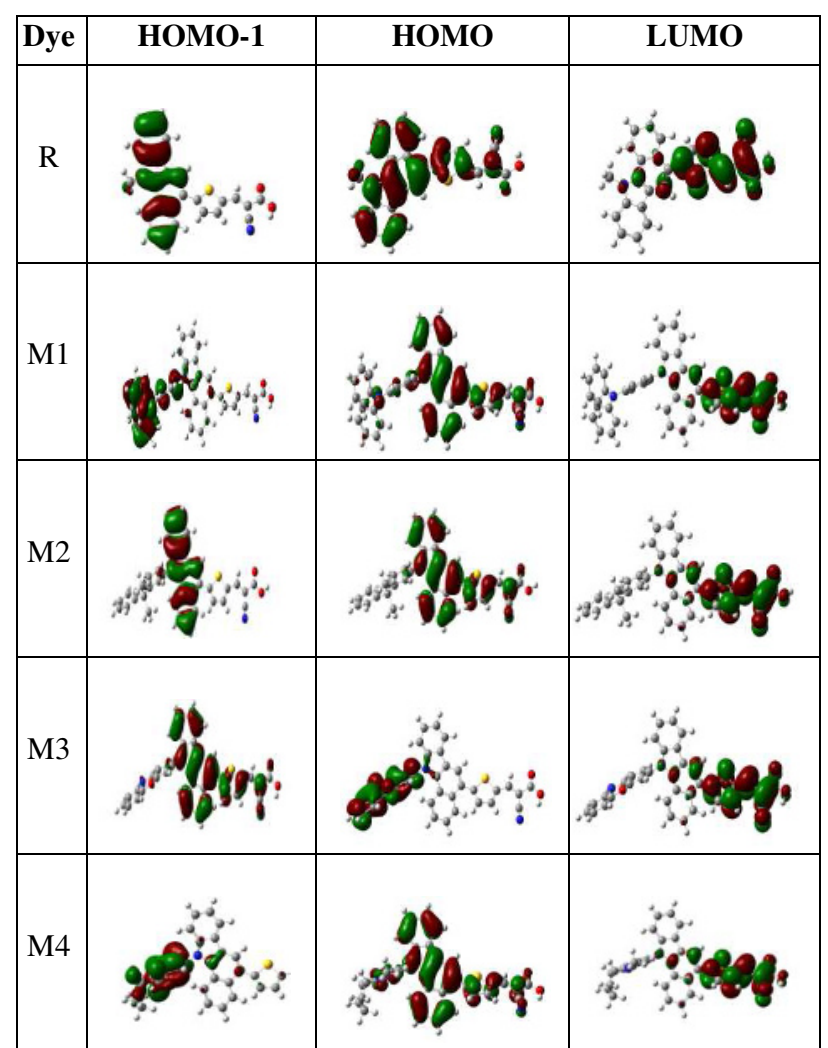

Fig. 3. Contour plots of frontier orbitals of studied dyes.

\subsection{Optical properties}

The optical properties of the five dyes (R, M1-M4) were investigated by UV-Vis absorption spectroscopy. These values are calculated by using TD-DFT/CAM-B3LYP/ 6-31(d,p) level. The obtained results of absorption wavelengths $\left(\lambda_{\max }\right)$, electronic vertical transition energies $\left(\mathrm{E}_{\mathrm{ex}}\right)$ and oscillator strengths $(f)$ of all dyes in solvent $\left(\mathrm{CH}_{3} \mathrm{Cl}\right)$ are listed in Table 1, and the corresponding simulated absorption spectra illustrated in Fig. 4.
Table 1. Absorption data for studied dyes in chloromethane solvent calculated by TD-DFT at CAM-B3LYP/6-31G(d,p)

\begin{tabular}{|l|c|c|c|c|c|}
\hline Dye & $\lambda_{\max }$ & $\mathbf{E}_{\text {ex }}$ & $\boldsymbol{f}$ & LHE & $\begin{array}{c}\text { MO/ } \\
\text { character }\end{array}$ \\
\hline $\mathrm{R}$ & 417.87 & 2.967 & 0.968 & 0.892 & $\mathrm{H} \rightarrow \mathrm{L}(0.65)$ \\
\hline M1 & 416.12 & 2.980 & 1.118 & 0.924 & $\mathrm{H}-1>\mathrm{L}(0.47)$ \\
\hline M2 & 409.67 & 3.026 & 1.132 & 0.926 & $\mathrm{H}>\mathrm{L}(0.65)$ \\
\hline M3 & 415.37 & 2.985 & 1.100 & 0.920 & $\mathrm{H}-1>\mathrm{L}(0.65)$ \\
\hline M4 & 418.87 & 2.960 & 1.073 & 0.915 & $\mathrm{H} \rightarrow \mathrm{L}(0.59)$ \\
\hline
\end{tabular}

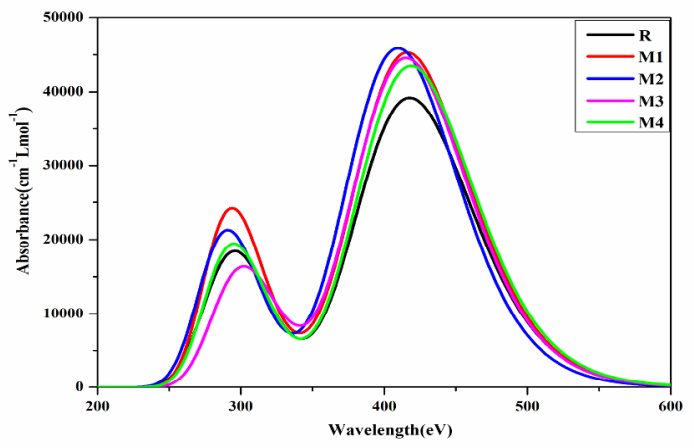

Fig. 4. Simulated UV-Vis optical absorption spectra of all dyes with data calculated by TD-DFT at CAM-B3LYP/6-31G(d,p) level.

The $\mathrm{R}$ molecule shows absorption maximum value of $417.87 \mathrm{~nm}$, while $\lambda_{\max }$ value of designed molecules (M1M4) is 416.12, 409.67, 415.37, and $418.87 \mathrm{~nm}$ respectively. From $\lambda_{\max }$ values it is observed that all dyes exhibit a strong absorption band in the visible region which can be assigned to an intramolecular charge transfer (ICT) between the various donating unit and the electron acceptor fragments which is beneficial to further increase the photo-to-electric conversion efficiency of the corresponding solar cells.

The oscillator strength $(f)$ is another descriptor that communicates the probability of absorption of electromagnetic radiation by transitions between the energy levels of an atom or molecule. The oscillator strength values of these dyes at the maximum absorption are presented in Table 1, revealing values in the range of 0.968-1.132. Besides the oscillator strength, another factor associated with the efficiency of DSSCs is the light harvesting efficiency (LHE). The LHE of these dyes must be as high as possible to maximize the photocurrent response. The LHE values for all these dyes range from 0.892 to 0.926 (Table 1). This slight difference between the LHE values indicates that all the sensitizers will give similar photocurrents.

\subsection{Photovoltaic properties}

The free energy of electron injection $\left(\Delta G_{\text {inject }}\right)$ and the free energy regeneration $\left(\Delta \mathrm{G}_{\mathrm{reg}}\right)$ are important parameters to analyze the relationship between the electronic structure and $\mathrm{J}_{\mathrm{sc}}$. Low $\Delta \mathrm{G}_{\text {inject }}$ and $\Delta \mathrm{G}_{\text {reg }}$ are required for fast electron transfer. The calculated values of these parameters of all dyes are evaluated according 
to Eqs. (5) and (6), and the corresponding data are summarized in Table 2.

Table 2. Estimated electrochemical parameters (in $\mathrm{eV}$ ) for all dyes.

\begin{tabular}{|l|c|c|c|c|c|}
\hline Dye & $\mathbf{E}^{\text {dye }}$ & $\mathbf{E}^{\text {dye* }}$ & $\Delta \mathbf{G}_{\text {inject }}$ & $\Delta \mathbf{G}_{\text {reg }}$ & $\mathbf{V}_{\text {oc }}$ \\
\hline R & 5.487 & 2.520 & -1.480 & 0.687 & 1.305 \\
\hline M1 & 5.394 & 2.414 & -1.586 & 0.594 & 1.368 \\
\hline M2 & 5.351 & 2.325 & -1.675 & 0.551 & 1.495 \\
\hline M3 & 5.304 & 2.319 & -1.681 & 0.504 & 1.367 \\
\hline M4 & 5.331 & 2.371 & -1.629 & 0.531 & 1.398 \\
\hline
\end{tabular}

Our study reveals that all the dyes have a negative $\Delta G_{\text {inject }}$ value, which indicates that the excited state energy levels are located above the $\mathrm{CB}$ of the semiconductor, which leads to a high electron injection efficiency from the excited dye to the $\mathrm{CB}$ of the $\mathrm{TiO}_{2}$. Moreover, the $\Delta \mathrm{G}_{\text {inject }}$ value calculated for all the studied dyes increases in the order $\mathrm{M} 3<\mathrm{M} 2<\mathrm{M} 4<\mathrm{M} 1<\mathrm{R}$ and $\Delta \mathrm{G}_{\text {reg }}$ in the order $\mathrm{M} 3<\mathrm{M} 4<\mathrm{M} 2<\mathrm{M} 1<\mathrm{R}$; these results reveal that dye M3 with phenoxazine as the terminal donor exhibits a high power conversion efficiency compared with the other compounds $\left(\Delta \mathrm{G}_{\text {inject }}=\right.$ $-1.681 \mathrm{eV}$ and $\Delta \mathrm{G}_{\text {reg }}=0.504 \mathrm{eV}$ ), leading to a high IPCE. In addition, the values of $\mathrm{J}_{\mathrm{sc}}$ and the open-circuit voltage $\left(\mathrm{V}_{\mathrm{oc}}\right)$ also influence the global power conversion efficiency. Based on Eq. (2), the $V_{\text {oc }}$ of the studied dyes increases in the order M2>M4> M3> M1> R, revealing that all designed dyes M1-M4 have larger $\mathrm{V}_{\mathrm{oc}}$ values than R. Based on these results, it can be concluded that a

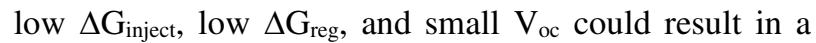
high efficiency. Consequently, the performance of DSSCs sensitized using M3 may be superior to when using other dyes, due to its favorable performance in terms of the above-mentioned factors obtained from our theoretical results.

\section{Conclusion}

A series of novel metal-free organic molecules (M1-M4) was theoretically designed from HQP-S (R), a recently synthesized dye. The main object of this work was to elucidate the effect of various terminal electron donors on the electronic, optical and photovoltaic properties of M1-M4. The ground-and excited-state properties of the designed dyes were calculated by using DFT and TDDFT methods, respectively. Our calculations reveal that, compared with dye R, dye M3 with phenoxazine as the terminal electron donor improves the performance potentially due to the narrow energy gap, broad absorption spectrum, appropriate FMO energy levels, lowest $\Delta \mathrm{G}_{\text {inject }}$ and $\Delta \mathrm{G}_{\text {reg values. }}$

\section{References}

1. W.-J. Fan, H. Shi, D.-Z. Tan, Z.-N. Xu, N.-K. Yua, J.-L. Zhao, Comput Mater Sci. 151, 34 (2018)
2. X. Xie, Z. Liu, W. Li, F. Bai, E. Lee, H. Zhang, Chem Phys Lett. 719, 39 (2019)

3. K. Cao, J. Lu, J. Cui, Y. Shen, W. Chen, G. Alemu, Z. Wang, H. Yuan, J. Xu, M. Wang, Y. Cheng, J Mater Chem A. 2, 4945 (2014)

4. Z. Tian, M. Huang, B. Zhao, H. Huang, X. Feng, Dye Pigment. 87, 181 (2010)

5. A. Amkassou, H. Zgou, Mater Today Proc. 13, 569 (2019)

6. M.K. Nazeeruddin, F. De Angelis, S. Fantacci, A. Selloni, G. Viscardi, P. Liska, S. Ito, B. Takeru, M. Grätzel, J. Am. Chem. Soc. 127, 16835 (2005)

7. C.A. Bignozzi, R. Argazzi, R. Boaretto, E. Busatto, S. Carli, F. Ronconi, S. Caramoria, Coord. Chem. Rev. 257, 1472 (2013)

8. Y. Bouzineb, A. Slimi, M. Raftani, A. Fitri, A. Touimi Benjelloun. M. Benzakour. M. Mcharf, M. Bouachrine, J. Mol. Model. 26, 346 (2020)

9. A. Slodek, D. Zych, G. Szafraniec-Gorol, P. Gnida, M. Vasylieva, E. Schab-Balcerzak, Materials 13, 2292 (2020)

10. L. Han, X. Meng, Y. Ke, H. Ye, Y. Cui, J. Photochem. Photobiol. A Chem. 376, 127 (2019)

11. M. J. Frisch, G. W. Trucks, H. B. Schlegel, G. E. Scuseria,M. A. Robb, J. R. Cheeseman, G. Scalmani, V. Barone, B. Mennucci, G. A. Petersson, H. Nakatsuji, M. Caricato, X. Li, H. P. Hratchian, A. F. Izmaylov, J. Bloino, G. Zheng, J. L. Sonnenberg, M.Hada, M. Ehara,K.Toyota,R. Fukuda, J. Hasegawa,M. Ishida, T. Nakajima, Y. Honda, O. Kitao, H. Nakai, T. Vreven, J. A. Montgomery, Jr., J. E. Peralta, F. Ogliaro, M. Bearpark, J. J. Heyd, E. Brothers, K. N. Kudin, V. N. Staroverov, R. Kobayashi, J. Normand, K. Raghavachari, A. Rendell, J. C. Burant, S. S. Iyengar, J. Tomasi, M. Cossi, N. Rega, J. M. Millam, M. Klene, J. E. Knox, J. B. Cross, V. Bakken, C. Adamo, J. Jaramillo, R. Gomperts, R. E. Stratmann, O. Yazyev, A. J. Austin, R. Cammi, C. Pomelli, J. W. Ochterski, R. L. Martin, K. Morokuma, V. G. Zakrzewski, G. A. Voth, P. Salvador, J. J. Dannenberg, S. Dapprich, A. D. Daniels, O*. Farkas, J. B. Foresman, J. V. Ortiz, J. Cioslowski, D. J. Fox, Gaussian 09, Revision A.02, Gaussian Inc., Wallingford CT, (2009).

12. C. Lee, W. Yang, R.G. Parr, Phys. Rev. B: Condens. Matter. 37, 785 (1988)

13. J. Tomasi, B. Mennucci, E. T. Cancès, J. Mol. Struct. 464, 211 (1999)

14. A. Fitri, A. Touimi Benjelloun, M. Benzakour, M. Mcharfi, M. Hamidi, M. Bouachrine, J. Mater. Environ. Sci. 7, 834 (2016)

15. H. Etabti, A. Fitri, A. Touimi Benjelloun, M. Hachi, M. Benzakour, M. Mcharfi, Res. Chem. Intermed. 47, 4257 (2021) 
16. D. Chattopadhyay, S. Lastella, S. Kim, F. Papadimitrakopoulos, J Am Chem Soc. 124, 728 (2002)

17. W. Sang-aroon, S. Saekow, V. Amornkitbamrung, J. Photochem. Photobiol. A Chem. 236, 35 (2012)

18. S.L. Chen, L.N. Yang, Z.S. Li, J. Power Sources 223, 86 (2013)

19. Z.-L. Zhang, L.-Y. Zou, A.-M. Ren, Y.-F. Liu, J.-K. Feng, C.-C. Sun, Dyes Pigments 96, 349 (2013)

20. A. Mahmood, M.H. Tahir, A. Irfan, A.G. AlSehemi, M.S. Al-Assiri, Comput. Theor. Chem. 1066, 94 (2015)

21. L.L. Sun, T. Zhang, J. Wang, H. Li, L.K. Yan, Z.M. Su, RSC Adv. 5, 39821 (2015)

22. S. Kim, J.K. L. ee, S.O. Kang, J. Ko, J.-H. Yum, S. Fantacci, F. De Angelis, D. Di Censo, Md. K. Nazeeruddin, M. Grätzel, J Am Chem Soc. 128, 16701 (2006)

23. M. Grätzel, Photoelectrochemical cells. In: Materials For Sustainable Energy: A Collection of Peer-Reviewed Research and Review Articles from Nature Publishing Group, World Scientific, $26(2011)$ 